\title{
Artigo Original \\ EVOLUÇÃO DAS FRATURAS INTRA-ARTICULARES DESVIADAS DO CALCÂNEO COM TRATAMENTO CIRÚRGICO
}

\author{
EVOLUTION OF CALCANEUS DEVIATED INTRA-JOINT FRACTURES SURGICALLY TREATED
}

\author{
Sidney Silva de Paula ${ }^{1}$, Maria de Lourdes Pessole Biondo-Simöes'², Richard LuzzI ${ }^{3}$
}

\begin{abstract}
RESUMO
Fraturas do calcâneo correspondem a $2 \%$ do total de fraturas do corpo humano. Apresentam acentuada importância social e grande impacto econômico, pois ocorrem em indivíduos economicamente ativos. Para reconhecer a evolução das fraturas intra-articulares desviadas do calcâneo, um estudo retrospectivo é apresentado. A amostra constituiu-se de 71 doentes com fratura de calcâneo intra-articular desviada, 63 homens (88,73\%) e 8 mulheres (11,27\%). A idade esteve entre 14 e 74 anos. Conforme a escala de ESSEX-LOPRESTI, 55 delas eram do tipo depressão articular $(77,46 \%)$ e 16 do tipo em língua (22,54\%). A incisão mais usada foi a lateral em L $(91,55 \%)$. Sessenta e uma das fraturas foram fixadas com placa "duplo H" (85,92\%), 9 necessitaram apenas de parafusos $(12,68 \%)$ e uma delas foi fixada com fios de Kirschner. Sete fraturas necessitaram de enxerto ósseo $(9,86 \%)$. O tempo médio de seguimento foi de 11,59 $\pm 6,72$ meses. Complicações precoces estiveram presentes em $33,82 \%$ dos doentes sendo mais comum a infecção e a necrose de pele. Complicações tardias foram identificadas em $63,38 \%$ dos doentes, principalmente edema residual e artrose. A incidência de complicações tardias não esteve relacionada ao tipo de fratura. As fraturas do tipo depressão articular contribuíram para a maior limitação das atividades $(p=0,0315)$. O ângulo de Böhler, medido no pós-operatório, apresentou relação direta com o resultado final e ângulos menores do que 20 graus determinam maior incidência de maus resultados $(p=0,0111)$. Observando a escala AOFAS, $59,26 \%$ de todos os doentes, evoluíram com bons e excelentes resultados.
\end{abstract}

Descritores: Traumatismos do pé; Fraturas; Fixação interna de fraturas; Calcâneo; Cicatrização

\section{SUMMARY}

Fractures of the calcaneus account for $2 \%$ of all human body fractures. They present a strong social importance and a great economical impact, because they affect economically active individuals. In order to recognize the evolution of calcaneus intrajoint fractures evolution, a retrospective study is presented here. The sample was constituted by 71 patients with deviated intrajoint fractures of the calcaneus, being 63 males (88.73\%) and 8 females (11.27\%). Ages ranged 14 to 74 years old. According to the ESSEX-LOPRESTI scale, 55 of them were joint-depression type (77.46\%) and 16 of tongue-kind 22.54\%). The most commonly used incision was the lateral L-shape kind (91.55\%). Sixty one fractures were fixed with a "double H" plate (85.92\%), 9 required only screws (12.68\%) and one was fixed with Kirschner wire. Seven fractures required bone graft (9.86\%). The average follow-up time was $11.59 \pm 6.72$ months. Early complications were present in $33.82 \%$ of the patients, the most common ones were infections and necrosis of the skin. Late complications were identified in $63.38 \%$ of the patients, the most common ones being residual edema and arthrosis. The incidence of late complications was not related to the type of fracture. Joint-depression type fractures contributed to a greater restraint of activities ( $p=0.0315)$. The Böhler angle, postoperatively measured, showed a direct relationship with the final outcome, and angles smaller than 20 degrees determine a greater incidence of poor results $(p=0.0111)$. According to the AOFAS scale, $59.26 \%$ of all patients developed good and excellent results.

Keywords: Foot injuries; Fractures; Internal fixation of fractures; Calcaneus; Wound healing

na redução fechada ou com mínima abertura e imobilização com gesso(1). A redução cruenta das fraturas articulares do calcâneo teve grande impulso após os trabalhos publicados por Palmer ${ }^{(2)}$ realizando abordagem cirúrgica por via lateral, redução dos fragmentos, correção do afundamento da superfície articular subtalar, preenchimento da falha óssea com enxerto ósseo e imobilização gessada. Posteriormente a técnica de Palmer foi modificada empregando-se a fixação da fratura com parafusos e duplo acesso, medial e lateral(3). Na década de 90 os autores passaram a utilizar o acesso lateral extenso ${ }^{(4,5)}$ e acrescentou-se a possibilidade do uso da placa em $\mathrm{Y}$ e parafusos $\mathrm{AO}$ (Arbeitsgemeinschaft für

Trabalho realizado Hospital Universitário Cajuru - PUCPR

Endereço para correspondência: Rua Ari José Valle, 1987, Santa Felicidade - CEP 82030-000, Curitiba - Paraná - E-mail: biondo@avalon.sul.com.br

1. Mestre em Clínica Cirúrgica pela PUCPR. Membro Titular da Sociedade Brasileira de Ortopedia e Traumatologia. Chefe do Serviço de Cirurgia do pé e tornozelo do Hospital Universitário Cajuru da PUCPR.

2. Doutora em Cirurgia Experimental pela UNIFESP-EPM. Professora Adjunta do Departamento de Cirurgia da UFPR e Professora Titular de Metodologia da Pesquisa da PUCPR. Titular do CBC.

3. Membro Titular da Sociedade Brasileira de Ortopedia e Traumatologia. Médico do Serviço de Cirurgia do pé e tornozelo do Hospital Universitário Cajuru da PUCPR. 
Osteosynthese) de $3,5 \mathrm{~mm}^{(6)}$. Outros autores fizeram propostas diferentes como a fixação percutânea ou minimamente invasi$\mathrm{va}^{(7)}$. Myerson e Manoli chamaram a atenção para a síndrome compartimental, nas fraturas do calcâneo, que deve ser tratada com fasciotomia imediata ${ }^{(8)}$. Com o advento da tomografia essas fraturas poderam ser mais bem estudadas e compreendidas e o tratamento racionalizado para cada situação.

A fratura do calcâneo apresenta acentuada importância social e econômica, pois ocorre em indivíduos economicamente ativos, na sua maioria trabalhadores braçais, que podem se tornar dependentes do sistema previdenciário público por muito tempo.

O objetivo deste estudo, retrospectivo, foi analisar os fatores envolvidos no tratamento cirúrgico e os resultados clínicos das fraturas intra-articulares desviadas do calcâneo.

\section{MATERIAL E MÉTODO}

O projeto de pesquisa deste estudo foi examinado e aprovado pelo Comitê de Ética de Pesquisa com Seres Humanos da Pontifícia Universidade Católica do Paraná.

Avaliaram-se os prontuários de 71 doentes com fratura de calcâneo intra-articular desviadas, atendidos no Hospital Universitário Cajuru-PUCPR, no período compreendido entre janeiro de 2000 e dezembro de 2003, que preencheram os critérios de inclusão: prontuário contendo todas as informações, isto é, desde a admissão no Serviço até a sua alta definitiva; ter idade igual ou superior a 12 anos e ter recebido tratamento cirúrgico.

Avaliou-se o sexo, a idade, o mecanismo do trauma, a existência de lesões associadas, se a fratura era ou não exposta e o lado acometido.

O estudo radiológico, para análise da fratura, consistiu de radiografia do calcâneo axial (incidência de Harris), perfil e incidências de Bròden. A fratura foi classificada conforme Essex-Lopresti, que se baseia em linhas de fratura primárias e secundárias. nos tipos: depressão articular e em língua.

Verificou-se se o pacientes foram operados imediatamente e quando não qual o intervalo entre a admissão e o tratamento operatório.

$\mathrm{Na}$ descrição do ato operatório verificou-se o tipo de incisão utilizada, modo como se fez o afastamento do retaIho cutâneo e como as fraturas foram fixadas (com placas "duplo H", com o tamanho variando de acordo com o comprimento do calcâneo e o traço da fratura, além de parafusos esponjosos 3.5 e eventualmente fios de Kirschner. Verificou-se ainda o emprego de enxerto ósseo e da drenagem por aspiração contínua, por 24 horas.

Observou-se a obediência ao protocolo do Serviço com a colocação de tala gessada suropodálica pelo período de duas semanas e de antibióticoprofilaxia com Cefazolina $1 \mathrm{~g}$ na indução anestésica e manutenção até 24 horas. Após a retirada da tala, incentivava-se o paciente a mobilizar o tornozelo, inicialmente de maneira passiva. Quando a consolidação era observada radiológicamente, a carga era iniciada com o uso de muletas axilares até a liberação total do apoio no membro acometido.

Verificaram-se as complicações precoces como: deiscência de pele com ou sem necrose, infecção, lesão do nervo sural e perda da redução. Entre as complicações tardias, pesquisou-se: edema residual, tendinite dos fibulares, artrose, osteomielite com ou sem retirada da placa, osteodistrofia e consolidação viciosa.

O resultado radiológico do tratamento cirúrgico foi feito pela análise do ângulo de Böhler pós-operatório que forneceu os dados das alterações da faceta articular posterior. Deveria ter variação entre 20 e 40 graus para que o resultado fosse considerado bom.

Os resultados foram avaliados clinicamente pela escala AOFAS para tornozelo e retropé (American Orthopaedic Foot and Ankle Society), que leva em consideração os seguintes itens: intensidade da dor; função (limitação das atividades e necessidade de suporte com orteses); distância máxima de marcha medidas em quarteirões; anormalidade da marcha; mobilidade sagital (flexão

\begin{tabular}{|c|c|}
\hline Parâmetro & Pontos \\
\hline \multicolumn{2}{|l|}{ 1. Dor (40 pontos) } \\
\hline Nenhuma & 40 \\
\hline Leve, ocasional & 30 \\
\hline Moderada, diária & 20 \\
\hline Intensa, quase sempre presente & 0 \\
\hline \multicolumn{2}{|l|}{ 2. Função (50pontos) } \\
\hline \multicolumn{2}{|l|}{ 2.1 Limitação das atividades e necessidade de suporte } \\
\hline Sem limitação, sem suportes & 10 \\
\hline Sem limitações às atividades diárias, limitação recreacional, sem suportes & 7 \\
\hline Limitação das atividades diárias e recreacionais, bengala & 4 \\
\hline Limitação importante das atividades diárias, muleta, andador,cadeira & 0 \\
\hline \multicolumn{2}{|l|}{2.2 Distância máxima de marcha (quarteirōes) } \\
\hline Maior do que 6 & 5 \\
\hline De 4 a 6 & 4 \\
\hline De 1 a 3 & 2 \\
\hline Menor do que 1 & 0 \\
\hline \multicolumn{2}{|l|}{ 2.3 Superficie de marcha } \\
\hline Sem dificuldade em qualquer superficie & 5 \\
\hline Alguma dificuldade em terrenos irregulares, escadas ou ladeiras & 3 \\
\hline Dificuldade intensa em terrenos irregulares, escadas ou ladeiras & 0 \\
\hline \multicolumn{2}{|l|}{2.4 Anormalidade da marcha } \\
\hline Nenhuma ou leve & 8 \\
\hline Óbvia & 4 \\
\hline Marcante & 0 \\
\hline \multicolumn{2}{|l|}{2.5 Mobilidade sagital (flexăo + extensão) } \\
\hline Normal ou restriçăo mínima ( $30^{\circ}$ ou mais) & 8 \\
\hline Restrição moderada $\left(15^{\circ}\right.$ a $\left.29^{\circ}\right)$ & 4 \\
\hline Restrição intensa (menor que $15^{\circ}$ ) & 0 \\
\hline \multicolumn{2}{|l|}{ 2.6 Mobilidade do retro-pé (inversão e eversão) } \\
\hline Normal ou restrição leve (75 a 100\%) & 6 \\
\hline Restrição moderada (25 a 74\%) & 3 \\
\hline Restrição intensa (menor do que 25\%) & 0 \\
\hline \multicolumn{2}{|l|}{2.7 Estabilidade do tornozelo e retro-pé (antero-posterior + varo-valgo) } \\
\hline Estável & 8 \\
\hline Instável & 0 \\
\hline \multicolumn{2}{|l|}{ 3. Alinhamento (10 pontos) } \\
\hline Bom - pé plantigrado com tornozelo e retro-pé alinhados & 10 \\
\hline Regular - pé plantigrado, algum desalinhamento, sem dor & 5 \\
\hline Mau - pé nâo plantigrado, desalinhamento importante e sintomático & 0 \\
\hline
\end{tabular}

Quadro 1 - Escala AOFAS (American Orthopaedic Foot and Ankle Society) de avaliação clínica do tornozelo e retropé + extensão); mobilidade do retropé (inversão + eversão) estabilidade do tornozelo e retropé (antero-posterior + varo-valgo) e alinhamento do pé e tornozelo. As notas de cada item eram somadas fornecendo pontos de 0 a 100. Os resultados eram considerados excelentes quando a pontuação oscilava entre 90 e 100 , bom quando entre 80 e 89, regular quando entre 70 e 79 e ruim quando menor do que 69 (Quadro 1). Considerou-se, ainda o retorno ou não ao trabalho.

Para a comparação dos grupos, em relação a variáveis quantitativas, foi usado o teste $\mathrm{t}$ de student para amostras independentes, levando-se em consideração a homogeneidade das varianças ou o teste não paramétrico de Mann-Whitney, quando apropriado. A condição de normalidade foi verificada pelo tes- 
te de Shapiro-Wilks. Para a comparação dos grupos em relação às variáveis categóricas foi usado o teste exato de Fisher. Um valor de $p \leq 0,05$ foi considerado estatisticamente significante.

\section{RESULTADOS}

Observou-se que entre os 71 doentes acompanhados houve predominância de homens. Estes eram em número de 63 (88,73\%) e 8 eram mulheres $(11,27 \%$ ) A idade esteve entre 14 e 74 anos com média de 41,41 anos e desvio padrão de 13,44 Verificou-se que 44 doentes (62\%) eram trabalhadores ligados à construção civil e $38 \%$ ligados à outras funções.

A queda de desnível foi o mecanismo responsável por 70 das fraturas $(98,59 \%)$. Apenas uma fratura teve como agente causal o impacto de um acidente de trânsito.

Sessenta e dois pacientes $(87,32 \%)$ apresentavam-se apenas com fratura de calcâneo. Nove (12,68\%) tinham outras lesões: traumatismo crâneo-encefálico, fratura de fêmur, fratura de joelho, fratura da coluna lombar, fratura do rádio e fratura de cotovelo. Exposição óssea esteve presente em um único caso $(1,41 \%)$. Constatou-se distribuição uniforme das fraturas, pois 35 estavam localizadas no calcâneo direito $(43,66 \%)$ e 36 no calcâneo esquerdo (45,07\%).

O estudo radiológico permitiu classificar as fraturas, conforme a escala de Essex-Lopresti (1952) e revelou que 55 delas eram do tipo depressão articular $(77,46 \%)$ e 16 , do tipo em língua.

Dos 71 pacientes, 11 foram operados imediatamente $(15,49 \%)$ e 60 o foram com um intervalo de tempo que variou entre 1 e 20 dias, com média de 3,85 $\pm 3,64$ dias.

As incisões utilizadas foram: a lateral em L, em 65 doentes (91,55\%); a associação da incisão lateral em L com a medial em 1 fratura $(1,41 \%)$ e o acesso percutâneo em 5 (7,04\%).

Sessenta e uma das fraturas foram fixadas com placa "duplo $\mathrm{H}$ " (85,92\%), 9 necessitaram apenas de parafusos (12,67\%), uma delas foi fixada com fios de Kirschner $(1,41 \%)$ e 7 necessitaram de enxerto ósseo $(9,86 \%)$.

O tempo médio de seguimento foi de 11,59 $\pm 6,72$ meses ( 4 a 47 meses). Constatou-se, entre os operados, 24 complicações precoces $(33,80 \%)$ (Tabela 1$)$. Entre elas a mais comum foi a infecção, que contribuiu com 10 casos (14,08\%), 5 vezes isolada $(7,04 \%), 3$ vezes associada com necrose da pele $(4,23 \%)$ e 2 vezes associada à deiscência da pele (2,82\%).

Quarenta e cinco fraturas evoluíram com complicações tardias (63,38\%) (Tabela 2). $\mathrm{O}$ edema residual contribuiu com 25 casos $(35,21 \%)$ apresentando-se isolado ou associado a outras seqüelas. A artrose existiu em 18 calcâneos $(25,35 \%)$. Outras seqüelas foram anotadas como: tendinite dos fibulares, exostose, osteomielite e consolidação viciosa. Estas complicações não estiveram relacionadas ao tipo de fratura (Tabela 3) e embora a artrose tenha contribuído com as complicações tardias, sua incidência não esteve relacionada ao tipo de fratura $(p=0,3266)$

O ângulo de Böhler, que indica as alterações da faceta articular posterior e é utilizado para qualificar a resolução da fratura, mostrou-se com variações entre 0 e 40 com média de 22,08 $\pm 8,95$, sem diferença significante quanto aos tipos de fratura. Esse ângulo determina a qualificação da resolução da fratura e esteve 24 vezes abaixo de $20^{\circ}$, traduzindo maus resultados, e 47 vezes acima de $20^{\circ}$, traduzindo bons resultados. Essa situação distribuiu-se de forma semelhante entre os dois tipos de fratura $(p=1,0000)$.

A classificação dos resultados segundo a escala AOFAS permitiu reconhecer que 42 fraturas $(59,15 \%)$ evoluíram com bons ou excelentes resultados e $29(40,85 \%)$ com resultados considerados regulares ou ruins (Tabela 4 ).

Encontrou-se relação entre o valor do ângulo de Böhler e a pontuação da tabela AOFAS (Tabela 5).

A escala AOFAS analisa dados de dor, limitação das atividades e necessidade de suporte, distância de marcha, anormalidades da marcha, mobilidade sagital (flexão e extensão do pé), mobilidade do retropé (inversão e eversão), estabilidade do tornozelo e retropé e alinhamento do tornozelo e retropé. A análise desses dados mostrou diferença na limitação das atividades quanto ao tipo de fratura (Tabela 6).

Dos 71 doentes, 14 (19,72\%) não retornaram ao trabalho, não se demonstrando que o tipo de fratura tenha tido alguma influência $(p=0,1664)$.

\section{DISCUSSÃO}

As fraturas articulares do calcâneo são lesões graves e costumam causar seqüelas permanentes e incapacitantes. Geralmente acometem indivíduos jovens, homens, numa faixa etária em que são economicamente ativos, o que pode determinar grande prejuízo socio-ecomômico. Na presente amostra, verificou-se que $88,73 \%$ dos pacientes eram do sexo masculino, tinham em média 41,41 $\pm 13,44$ anos. A observação da distribuição estratificada dos doentes demonstrou que $85,92 \%$ deles estavam compreendidos entre os 20 e os 60 anos e apenas 7 eram aposentados, reforçando a afirmativa de que acometem indivíduos que estão em pleno exercício de suas funções sociais.

$\mathrm{O}$ agente causal das fraturas intra-articulares do calcâneo mais frequente, relatado na literatura, é a queda de desnível ${ }^{l(1,9,10)}$ o que se confirmou neste levantamento, onde a queda de desnível foi responsável por $98,59 \%$ das fraturas.

Devido ao mecanismo axial de trauma, existe a possibilidade de lesões associadas. Autores relatam este fato ocorrendo em percentuais que oscilam entre 8,5 e $46 \%$ dos pacientes ${ }^{(9-13)}$. Encontrou-se, nesse levantamento,

\begin{tabular}{lcc}
\hline \multicolumn{1}{c}{ Tipo } & Freqüência & Percentual \\
\hline & & \\
Necrose de pele & 7 & 9,86 \\
Lesão do nervo sural & 1 & 1,41 \\
Deiscência da pele & 5 & 7,04 \\
Perda da redução & 1 & 1,41 \\
Infecção & 5 & 7,04 \\
Infecção + deiscência de pele & 2 & 2,82 \\
Infecção + necrose de pele & 3 & 4,23 \\
\hline
\end{tabular}

Tabela 1 - Complicações precoces

\begin{tabular}{lcr}
\hline \multicolumn{1}{c}{ Tipo } & Freqüência & Percentual \\
\hline Edema & 18 & \\
Edema + tendinite & 4 & 25,35 \\
Edema + exostose & 1 & 5,63 \\
Edema +compressão n.sural & 1 & 1,41 \\
Edema + osteodistrofia & 1 & 1,41 \\
Artrose & 18 & 1,41 \\
Artrose + osteomielite & 1 & 25,35 \\
Osteomielite & 3 & 1,41 \\
Tendinite dos fibulares & 2 & 4,22 \\
Retirada da placa & 1 & 2,82 \\
Consolidação viciosa & 1 & 1,41 \\
\hline
\end{tabular}

Tabela 2 - Complicações tardias outras lesões em $12,68 \%$ d doentes. Entre elas: traumatismo crâneo-encefálico, fratura do fêmur, do joelho, da coluna lombar, do rádio e do cotovelo e uma fratura exposta.

A classificação radiológica de Essex-Lopresti (1952) é clássica. Determina a linha de fratura, permitindo o planejamento do tratamento. A classificação tomográfica auxilia na avaliação da gravidade e do prognóstico da lesão sendo a classificação de Sanders e Gregory a mais utilizada ${ }^{(14)}$. Entretanto, as classificações tomográficas não são uniformes e cada grupo procura criar sua própria classificação o que dificulta a comparação de resultados, bem como o reconhecimento do tipo de lesão que descrevem. Reconhece-se que a tomografia é um excelente exame para identificação dos detalhes 
de fragmentos e comprometimento da articulação, porém esse exame não está disponível em todos os serviços. Essa limitação justifica a utilização da classificação radiológica. De acordo com a classificação de Essex-Lopresti, as fraturas intra-articulares podem ser em língua ou com depressão articular. Na maioria das casuísticas as fraturas do tipo depressão articular são as mais incidentes contribuindo com 43 a $61 \%$ das fraturas intra-articulares ${ }^{(11,15,16)}$. No levantamento que se apresenta, encontrou-se $77,46 \%$ de fraturas do tipo depressão articular e $22,54 \%$ do tipo língua. É interessante relacionar 0 tipo de fratura com a limitação das atividades gerais após a consolidação, pois encontrou-se nas fraturas do tipo depressão articular maior incidência de limitações $(p=0,0315)$.

Para o tratamento cirúrgico aberto, existe o consenso de aguardar um tempo entre o trauma e a operação, entre 7 a 14 dias para que haja diminuição do edema e para a prevenção da formação de flictenas, exceto nas fraturas expostas que devem receber tratamento cirúrgico imediato(13,14,17) ou quando for indicada a fixação percutânea(7). Nesse levantamento, o tempo entre o trauma e a operação das 71 fraturas foi em média 3,85 $\pm 3,64$ dias, sendo que 11 delas foram operadas imediatamente (15,49\%).

A via de acesso lateral em "L estendido" tem sido muito utilizada, pois permite melhor visibilidade da fratura, redução dos fragmentos e fixação interna ${ }^{(9-12,14,18-20)}$. Neste

estudo, o acesso lateral em "L estendido" mostrou-se eficiente em $91,55 \%$ dos casos.

A utilização de enxerto ósseo é controversa, existindo os que o consideram osteoindutor e osteocondutor ${ }^{(15,17)}$ e os que o consideram desnecessário(21). Deve-se lembrar que o uso de enxerto ósseo eleva a incidência de morbidades, pois existe mais uma incisão e a retirada de enxerto. Nesse levantamento o enxerto ósseo, obtido do ilíaco, foi aplicado em 7 das 74 fraturas analisadas, número muito pequeno para permitir conclusão quanto ao seu uso ou não. A utilização de materiais de osteossíntese diversos variou conforme o tamanho dos fragmentos; grandes fragmentos foram fixados com parafusos; fraturas com maior cominuição foram fixadas com placa e uma fratura exposta foi fixada com fios de Kirchner

Complicações precoces podem acompanhar a evolução do tratamento das fraturas intra-articulares do calcâneo. Entre elas, pode-se encontrar a deiscência de pele com ou sem necrose, a infecção, a lesão do nervo sural, a perda da redução e, ainda, a síndrome compartimental pela formação de hematoma ${ }^{(8)}$. Embora a incisão em "L estendido" seja realizada de forma a afastar, anteriormente, o nervo sural e a artéria fibular, necroses da porção anterior do retalho são observadas ou por lesão inadvertida da artéria ou de seus ramos ou por tração excessiva do retalho levando à isquemia. $\mathrm{Na}$ literatura as complicações precoces mais frequentes foram a necrose de pele variando de $11 \%$ a $40 \%$ e a infecção variando de $3,3 \%$ a $22 \%(3,6,9,12,18,20,22)$. Neste estudo, encontrouse $33,80 \%$ de complicações precoces, estando a infecção presente em $14,08 \%$ dos casos, associada ou não à deiscência ou à necrose da pele e a infecção em 7,04\%.

As complicações tardias são importantes visto que levam à incapacitação para o trabalho e para as atividades gerais. Alguns pacientes necessitam de calçados especiais pela presença de deformidades. Entre as complicações tardias, encontra-se a osteomielite, a mais temida, podendo em situações raras levar à amputação. Pode-se ter, ainda, a artrose que, levando à artrodese, é a complicação mais limitante. Outras situações podem aparecer como: edema, dor crônica, anormalidades de marcha, tendinite dos fibulares, restrição de mobilidade e não alinhamento do pé(1,6,18,20). Sanders $^{(1)}$ afirma que é necessária a redução anatômica da articulação subtalar para obter bons e excelentes resultados, porém isso não é garantia destes, provavelmente devido à lesão da cartilagem pelo trauma além do que os resultados seriam piores quanto maior fosse o número de fragmentos intra-articulares. 
O ângulo de Böhler, considerado normal com medidas que variam entre $20^{\circ}$ e $40^{\circ}$, é utilizado para indicar as alterações da faceta articular posterior e para qualificar a resolução da fratura. Loucks e Buckley ${ }^{(19)}$ realizaram estudo prospectivo e randomizado para a avaliação do ângulo de Böhler e sua correlação com os resultados do tratamento da fratura. Observaram que o tratamento cirúrgico melhorava a graduação do ângulo e também a condição funcional. Afirmaram que fraturas com ângulo de Böhler marcadamente diminuído, no pós-trauma imediato, apresentavam resultados ruins e sugeriram que a alta energia do trauma produza achatamento do ângulo, com maior lesão óssea, e das partes moles. Encontrou-se, no atual levantamento, variações entre $0^{\circ}$ e $40^{\circ}$, com média de $22,08^{\circ}$ $\pm 8,95^{\circ}$, sem diferença significante quanto aos tipos de fratura. Observou-se que o valor deste ângulo apresentou relação com a qualidade do resultado. Assim é que $70,21 \%$ das reduções com ângulo maior do que $20^{\circ}$ apresentaram resultados bons e excelentes, enquanto que apenas $37,50 \%$ das reduções abaixo de 20 o mostraram esse resultado $(p=0,0111)$. A restauração do ângulo está diretamente relacionada a qualidade da redução dos fragmentos.

Na avaliação dos resultados pela escala AOFAS encontramos na literatura índices que variam entre $42,22 \%$ a $62 \%$ de resultados excelentes ${ }^{(19,21,23)}$. Neste estudo os resultados foram considerados bons e excelentes em 59,15\%. Não se pode afirmar, com certeza, que o tipo de fratura possa ter influenciado a pontuação, pois a amostra aqui estudada de fraturas tipo língua é pequena se comparada à do tipo depressão articular. A escala foi subdividida nos seus itens para melhor avaliação dos resultados, sendo significativa a limitação das atividades nas fraturas tipo depressão articular ( $p=0,0315)$.

O'Farrel et al(24) relataram que $66,66 \%$ dos pacientes operados retornaram ao trabalho, puderam caminhar mais do que $4 \mathrm{~km}$ sem mudanças no tamanho do calçado. Esses autores compararam seus resultados, obtidos com doentes operados, com os de não operados e verificaram que entre esses últimos $12 \%$ retornaram ao trabalho e $66,66 \%$ tiveram que mudar o tamanho do calçado. Tennent et al(22) mostraram que $94 \%$ dos seus doentes retornaram ao trabalho num tempo médio de 6 meses e Asik e Sem(12) e $68,42 \%$ dos pacientes retornaram ao trabalho com capacidade total em 2 anos. Buckley et al ${ }^{(18)}$ fizeram um estudo prospectivo, randomizado e multicêntrico comparando o tratamento cirúrgico com o conservador para as fraturas intra-articulares desviadas do

\section{REFERÊNCIAS BIBLIOGRÁFICAS}

1. Sanders R. Displaced intra-articular fractures of the calcaneus. J Bone Joint Surg Am. 2000; 82:225-50.

2. Palmer I. The mechanism and treatment of fractures of the calcaneus. J Bone Joint Surg Am. 1948; 30:2-8.

3. Stephenson JR. Treatment of displaced intra-articular fractures of the calcaneus using medial and lateral approaches, internal fixation and early motion. J Bone Joint Surg Am. 1987; 69:115-30

4. Lowery RB, Calhoun JH. Fractures of the calcaneus. Part I: anatomy, injury mecanism, and classification. Foot Ankle Int. 1996; 17:230-5.

5. Lowery RB, Calhoun JH. Fractures of the calcaneus. Part II: treatment. Foot Ankle Int. 1996; 17:360-6.

6. Santin RAL, Fonseca Filho FF, Mercadante MT, Ferreira RC, Roncatto CE, Mazotti JP et al.. Tratamento operatório das fraturas articulartes do calcâneo com placa "duplo H". Rev Bras Ortop. 1995; 30:377-84.

7. Tornetta P. Percutaneous treatment of calcaneal fractures. Clin Orthop. 2000; 375:91 6.

8. Myerson M, Manoli A. Compartment syndromes of the foot after calcaneal fractures. Clin Orthop. 1993; 290:142-50.

9. Harvey EJ, Grujic L, Early JS, Benirschke SK, Sangeorzan BJ. Morbidity associated with ORIF of intra-articular calcaneus fractures using a lateral approach. Foot Ankle Int. 2001; 22:868-73.

10. Köberle G, Oliveira AC, Sandoval PS. Fraturas intra-articulares do calcâneo. Rev Bras Ortop. 1996; 31:477-80.

11. Moraes Filho DC, Provenzano E, Mattos JR, Batista LC, Galbiatti JA, Ferreira JCD et al.. Avaliação preliminar do tratamento cirúrgico de fraturas inta-articulares do calcâneo. Rev Bras Ortop. 1998;3:511-8.

12. Asik M, Sen $C$. Surgical management of intra-articular fractures of the calcaneus. Arch Orthop Trauma Surg. 2002; 122:354-9.

13. Heier KA, Infante AF, Walling AK, Sanders RW. Open fractures of the calcaneus: soft-tissue injury determines outcome. J Bone Joint Surg Am. 2003; 85:2276-82. calcâneo. Referiram que um método de tratamento não é melhor do que o outro, principalmente em grupos sem estratificação, porém, após remoção do dado que alguns pacientes recebiam remuneração por afastamento do trabalho, os resultados foram significativamente melhores no grupo de pacientes operados. Esse dado não foi possível avaliar no nosso estudo, porém existe o indício de que os pacientes que têm alguma remuneração pelo afastamento do trabalho, apresentam piores resultados. É difícil não ter esse resultado mascarado, visto que é um dado informativo do paciente. Apesar disso, $80,28 \%$ dos doentes aqui mostrados retornaram ao trabalho.

Em se tratando de resultados e seqüelas, é possível que um acompanhamento por um tempo maior possa trazer melhores informações, pois, como já se comentou, o tempo médio de acompanhamento neste estudo esteve em torno de um ano (11,59 $\pm 6,72$ meses)

Apesar deste estudo ter sido retrospectivo, serviu para que se pudesse reconhecer a evolução dos doentes tratados no Hospital Universitário Cajuru-PUCPR. Pode-se ver que os resultados foram muito semelhantes aos relatados na literatura. Serviu ainda para que se criasse a consciência de que melhor seria o desenvolvimento de protocolos de tratamento que possibilitassem estudos prospectivos, os quais forneceriam informações mais fidedignas, tanto das fraturas, no pré-operatório, quanto de suas evoluções.

\section{CONCLUSÕES}

Esta análise retrospectiva das fraturas intra-articulares do calcâneo permitiu verificar que: o tipo mais freqüente de fratura, conforme a classificação Essex-Lopresti, foi a do tipo depressão articular; as complicações precoces estiveram presentes em $33,82 \%$ dos doentes e as mais comuns foram a infecção $(14,08 \%)$ e a necrose de pele $(9,86 \%)$; as complicações tardias foram identificadas em $63,38 \%$ dos doentes e as mais comuns foram o edema residual (25,35\%) e a artrose (25,35\%); a incidência de complicações tardias não esteve relacionada ao tipo de fratura; as fraturas do tipo depressão articular contribuíram para a maior limitação das atividades $(p=0,0315)$; o ângulo de Böhler, medido no pós-operatório, apresentou relação direta com o resultado final e ângulos menores do que 20 graus determinam maior incidência de maus resultados ( $p=0,0111)$; e observando a escala AOFAS, $59,26 \%$ de todos os doentes evoluíram com bons e excelentes resultados.

14. Sanders R, Gregory P. Operative treatment of intra-articular fractures of the calcaneus. Orthop Clin North Am. 1995; 26:203-14.

15. Leung KS, Yuen KM, Chan WS. Operative treatment of displaced intra-articular fractures of the calcaneum: medium-term results. J Bone Joint Surg Br. 1993; 75:196 201

16. Kennedy JG, Jan WM. McGuinness AJ, Barry K, Curtin J, Cashman WF et al. An outcomes assessment of intra-articular calcaneal fractures, using patient and physician's assessment profiles. Injury 2003; 34:932-6.

17. Barei DP, Bellabarba C, Sangeorzan BJ, Benirschke SK. Fractures of the calcaneus. Orthop Clin North Am. 2002; 33:263-85.

18. Buckley R, Tough S, McCormack R, Pate G, Leighton R, Patrie D et al. Operative compared with nonoperative treatment of displaced intra-articular calcaneal fractures: a prospective, randomized, controlled multicenter trial. J Bone Joint Surg Am. 2002; a prospectiver $1733-44$.

19. Loucks C, Buckley R. Böhler's angle: correlation with outcome in displaced intraarticular calcaneal fractures. J Orthop Trauma. 1999; 13:554-8.

20. Murachovski J, Martinelli MO, Ferreira RC, Fonseca Filho FF. Fratura articular do calcâneo: resultado clínico-funcional do tratamento cirúrgico. Rev Bras Ortop. 2000; 35:314-24.

21. Longino D, Buckley RE. Bone graft in the operative treatment of displaced intraarticular calcaneal fractures: is it helpful ? J Orthop Trauma. 2001; 15:280-6.

22. Tennent TD, Calder PR, Salisbury RD, Allen PW, Eastwood DM. The operative management of displaced intra-articular fractures of calcaneum: a two center study using defined protocol. Injury 2001; 32:491-6.

23. Prado Jr I, Rocha MA, Rezende RR. Tratamento cirúrgico das fraturas intra-articulares desviadas do calcâneo, através de osteossíntese interna, sem enxerto ósseo. Rev Bras Ortop. 1999; 34:421-8.

24. O'Farrel DA, O'Byrne JM, McCabe JP, Stephens MM. Fractures of the os calcis: improved results with internal fixation. Injury 1993; 24:263-5. 